\title{
Variantes «de tres colores» tardías en la alfarería Santa María de Yocavil, Noroeste argentino. Aportes para la diacronía de un estilo regional
}

\author{
Valeria Palamarczuk \\ Museo Etnográfico «Juan B. Ambrosetti», Universidad de Buenos Aires - CONICET \\ valepala@yahoo.com.ar
}

Recibido: 7 de enero de 2013

Aceptado: 7 de octubre de 2013

\begin{abstract}
RESUMEN
A partir del trabajo con colecciones arqueológicas de museos se presenta un conjunto de vasijas Santa María «de tres colores» (negro y rojo sobre blanco), exponentes muy tardíos de la Tradición Santa María de la región de Yocavil, Noroeste Argentino. Algunas son vasijas únicas o rarezas; otras se repiten y nos permiten reconocer variantes con rasgos muy consistentes. La descripción incluye una comparación que establece contrastes con las variantes Santa María «tricolor» clásicas, propias de momentos más tempranos en la producción del estilo. La observación de patrones en los modos de aplicación de la pintura roja y sus tonalidades ayuda a delinear criterios para la identificación de estas variantes santamarianas en piezas completas y conjuntos fragmentarios, permitiendo su empleo como un valioso indicador cronológico.
\end{abstract}

Palabras clave: Cerámica arqueológica, estilo Santa María, Yocavil, Noroeste Argentino.

\section{Late Variants with «Three Colors» in Santa Maria Pottery from Yocavil, Argenti- nean Northwest. Contributions to a Regional Style Chronology}

\begin{abstract}
Based on the work with archaeological collections from different museums, we present a set of Santa María «three colors» (black and red on white) ceramics, very late exponents of the Santa María Tradition from the Yocavil region in the Argentinean Northwest. Some of those ceramics are unique or very rare; others have the same patterns and allow us to recognize variants with very consistent characteristics. The description includes a comparison that establishes contrasts with Santa Maria «tricolor» classic variants, typical of earlier times of this style production. The observation of the pattern in the application of the red paint and its tones helps to delineate criteria for the identification of these Santa María variants, both in complete pieces and fragmentary sets, allowing its use as a valuable chronological indicator.
\end{abstract}

Key words: Archaeological pottery, Santa María style, Yocavil, Argentinean Northwest.

Sumario: 1. Introducción, o por qué continuar en el siglo XXI con estudios tipológicos. 2. Los estudios cronológicos sobre la cerámica Santa María de Yocavil. 3. Método de estudio. 4. Las Variantes Santa María «de tres colores». 5. Comparaciones, síntesis y comentarios finales. 6. Referencias bibliográficas.

\section{Introducción, o por qué continuar en el siglo XXI con estudios tipológicos}

Establecer agrupamientos o series de materiales con valor cronológico ha sido en décadas pasadas un objetivo importante en la arqueología del Noroeste argentino (NOA). En especial, la diacronización de los estilos cerámicos fue considerada de gran utilidad para ponderar la temporalidad de contextos funerarios y de asentamientos del período agroalfarero. Para el caso de la región de Yocavil, en el área valliserrana del NOA, esta problemática tuvo su momento de gran auge entre las décadas de los años 50 y 70 con estudios que incluyeron la definición de tipos, el análisis 
de asociaciones estilísticas en contextos funerarios, la seriación contextual y la seriación estilística, con énfasis en materiales del Período Tardío e Inca, para luego ceder terreno a otros temas y tendencias metodológicas. De la mano de la expansión de los lineamientos de la arqueología procesual, los trabajos locales sobre tipología cerámica comenzaron a declinar y perder prestigio cuando todavía las descripciones básicas debían ser ampliadas y publicadas. En los últimos años se ha retomado el interés por los estudios cerámicos desde múltiples líneas como la escala y relaciones sociales involucradas en su producción, la tecnología, el simbolismo y, nuevamente, su cronología.

La tradición estilística santamariana representa un sistema de diseño de gran expansión regional durante las épocas tardías, plasmado sobre diferentes soportes materiales, como el arte rupestre, los textiles, la talla en madera y hueso, la metalurgia y la alfarería. Entre ellos, los dos últimos sobresalen debido a su perdurabilidad y abundancia; los museos de diferentes puntos del mundo los cuentan entre sus anaqueles y son los objetos que han atraído con mayor frecuencia la mirada curiosa de los investigadores.

En el caso de la cerámica Santa María de Yocavil las indagaciones generales sobre su cronología relativa se centraron casi con exclusividad en las dos formas de vasijas principales por su frecuencia: las urnas funerarias o tinajas y los pucos o cuencos. La suma de estos aportes fundó una base útil para delinear tendencias generales o de trazo grueso en la diacronización de los estilos alfareros tardíos, que continúa empleándose en análisis modernos. Por ejemplo, en relación a la forma y las proporciones, se reconoció que aquellas urnas con cuellos proporcionalmente más elongados que su cuerpo eran más modernas que aquellas de cuellos más cortos. En relación a las técnicas decorativas se estableció que la aplicación de pastillaje figurando cejas, ojos, brazos, etc. eran atributos de las urnas más tempranas. Del mismo modo, el puco con cuello se considera una clase de forma que surge tardíamente. También se generó un consenso sobre la mayor antigüedad de las variantes tricolores (negro y rojo sobre blanco), respecto de las bicolores (negro sobre blanco).

Pero toda generalización excluye ciertos casos y la distinción entre dos macro grupos santamarianos diacrónicos (tricolor y bicolor) no es una excepción. Así como se observaron escasos ejemplos de vasijas Santa María negro sobre blanco muy tempranas, también existen vasijas Santa María donde se conjugan los colores blanco, negro y rojo, para las que inferimos una temporalidad más tardía en base a sus cualidades intrínsecas (formas, relaciones métricas, esquemas de diseño) e información contextual (características del contexto de hallazgo y asociaciones).

En este artículo se presentan algunas cerámicas minoritarias, escasamente ilustradas en publicaciones. Se trata de piezas Santa María, en cuyos diseños se han empleado tres colores (blanco, negro y rojo), pero que, a diferencia de la cerámica Santa María tricolor clásica, exponente de la primera parte del Período Tardío, se habrían elaborado y usado en momentos más modernos (Tardío Final, de influencia incaica y Colonial Temprano). Integran la muestra urnas, pucos y otras piezas de formas poco convencionales.

Lejos de pretender la descomposición del modelo cronológico básico elaborado con esfuerzo y creatividad, este trabajo se propone ampliarlo incluyendo casos que 
no habían sido contemplados. De hecho nos valemos constantemente de elementos apuntados en estos antecedentes.

A lo largo del texto y apoyándonos en ilustraciones de vasijas enteras, veremos cómo algunas de estas variantes Santa María «de tres colores» presentan patrones o esquemas, schematta sensu Jernigan (1986), a partir de los cuales pueden ser distinguidas de los modelos más tempranos. Percibir estas diferencias es muy importante, pues con frecuencia empleamos a los estilos cerámicos como indicadores de la cronología de los contextos. En particular interesa definir criterios que sean útiles para la clasificación de conjuntos de fragmentos. Hasta el momento esta discriminación en los conjuntos de fragmentos tricolores no se ha realizado.

Las variantes «de tres colores» tardías son numéricamente muy minoritarias, por lo tanto su desestimación en el estudio de grandes conjuntos de fragmentos podría impactar poco en los resultados y en las interpretaciones que en ellos se basen. Pero en el caso de conjuntos pequeños de fragmentos, las consecuencias de este sesgo pueden ser más graves, pudiendo ocasionar diagnósticos cronológicos equivocados. Las posibilidades de clasificación de un conjunto de fragmentos cerámicos varían de acuerdo al nivel de fragmentación y alteración general. Lo ideal es emplear todos los elementos de distinción posibles. La fragmentación hace que en muchos casos no podamos apreciar las formas ni las unidades de diseño completas, por esto es importante que conozcamos los modelos de vasijas enteras.

Necesitamos entonces ir refinando nuestros conocimientos acerca de la dimensión temporal y espacial de las variantes estilísticas, tema sobre el que se ha avanzado mucho pero sobre el que no podemos decir que constituya una etapa «superada» en la arqueología de la región. Quizás el objetivo de este tipo de enfoque sea considerado como propio de momentos iniciales de la disciplina, la que en la actualidad debería ocuparse de cuestiones que trasciendan la mera tipología, y se comparte aquí esa aspiración a lograr trabajos explicativos, pero esos trabajos deben sustentarse sobre bases sólidas. Explorar al máximo y en diferentes dimensiones el potencial informativo en los materiales es un paso para reforzar esas bases.

\section{Los estudios cronológicos sobre la cerámica Santa María de Yocavil}

La cerámica Santa María es uno de los estilos alfareros mayoritarios del Período Tardío en los Valles Calchaquíes, área valliserrana del Noroeste argentino. Quizás debido a su abundancia, pero especialmente a lo llamativo de sus formas y diseños, en los que abundan las representaciones figurativas naturalistas y fantásticas -que siempre parecen más permeables o accesibles a los intentos de interpretación de los significados simbólicos que las representaciones abstractas-, ha fascinado a los investigadores desde las épocas iniciales de la antropología y la arqueología. Bregante (1926) sistematizó las diferentes formas del estilo santamariano y definió su distribución espacial en una vasta extensión de los valles calchaquíes. Aportes más modernos (Serrano 1958; Baldini 1980; Caviglia 1985; Nastri 1999) han permitido, entre otras cosas, conocer las variantes regionales, tomando como base al grupo morfológico de las urnas funerarias (tinajas). Debemos a Caviglia (1985) el diseño más reciente de 
regionalización del estilo. Este autor reconoce al menos dos tradiciones estilísticas en el conjunto santamariano: la Tradición Yocavil propia del valle de Santa María o Yocavil, el valle del Cajón, el valle de Tafí, y el piedemonte oriental en la provincia de Tucumán, y la Tradición Calchaquí correspondiente a los sectores medio y septentrional del valle Calchaquí. Luego propone tentativamente otras dos regiones en las que la cerámica santamariana presenta rasgos propios, que habilitarían el planteamiento de diferentes tradiciones: la Tradición Valle Arriba en el sector meridional del valle Cachaquí y norte de Yocavil, donde confluyen los valles del Cajón, Calchaquí y Yocavil, y la Tradición Pampa Grande-Santa Bárbara en la zona de la Quebrada de Las Conchas-Guachipas y sierras de Pampa Grande.

De las mencionadas tradiciones, quizás sea la Tradición Yocavil la más estudiada. Con una notable continuidad en el tiempo, que se extiende entre los siglos XI y XVII (Greco 2012), el problema de la diferenciación cronológica de sus variantes comenzó a perfilarse a partir de la década del 50, cuando la arqueología regional se volcaba hacia el establecimiento de secuencias regionales.

Los trabajos de Cigliano y Márquez Miranda (Cigliano 1958; Márquez y Cigliano 1957), apoyados en el cuadro cronológico del NOA de González (1955) que postula un momento Santa María I y un momento Santa María II-Paya Inca, deslindan con propósitos de diacronización del estilo cerámico un grupo al que se llamó Santa María tricolor, y otro al que se llamó Santa María bicolor. El análisis se basó en los materiales de la colección Benjamín Muñiz Barreto, que fueron recolectados en los segmentos central y sur del valle de Yocavil y sur del valle del Cajón. Contemplando esta distinción en la cerámica se plantearon dos momentos o facies dentro del período cultural representado por la cerámica santamariana. El primer momento o facie tricolor se calificó como «de gran auge decorativo», mientras que el segundo o facie bicolor se consideró «más limitado y acaso ligeramente declinante (al cual aparecen vinculadas formas francamente híbridas o decadentes)» (Márquez y Cigliano 1957: 5).

Serrano (1967) planteó un modelo que invertía la relación temporal del bicolor -al que consideraba de un origen temprano y luego de extendida perduración- y el tricolor, al que consideraba tardío. Aunque esta propuesta no logró consenso es interesante tener presente que se basó en apreciaciones sobre cerámica que trascendía las fronteras de la Tradición Yocavil.

Durante la década de los años 70 se programaron los conocidos ensayos de seriación estilística para el santamariano de Yocavil. La propuesta original fue desarrollada para la seriación cronológica de urnas santamarianas por Weber (1978). El ejercicio consideró la tabulación de variables morfológicas, métricas y de diseño. En las matrices de seriación se volcaron los atributos registrados en cada vasija, ordenando los ejemplares de la muestra ${ }^{1}$ a partir de las variables compartidas en una serie con valor cronológico. Las piezas más cercanas serían las más similares y de ello se infiere su contemporaneidad o mayor cercanía en la dimensión temporal. Las vasijas ubicadas en los extremos de la serie marcarían el inicio y el fin respectivamente de la

\footnotetext{
${ }^{1}$ Para ese trabajo se utilizó un total de 94 urnas, en su mayoría de la colección Zavaleta del Field Museum of Natural History de Chicago y también otras urnas ilustradas en diferentes publicaciones.
} 
producción del estilo. La serie se segmentó en cinco fases con valor cronológico, las tres primeras (I, II, y III) eran principalmente tricolores y las dos últimas (IV y V), principalmente bicolores (destacado nuestro).

Perrotta y Podestá repitieron este ejercicio con piezas de la colección Benjamín Muñiz Barreto del Museo de La Plata. Este trabajo confirmó, a partir de una muestra independiente, las tendencias planteadas en el trabajo original, al cual aportó solidez incluyendo información contextual. Las autoras agregaron una fase inicial a la que llamaron fase 0. De acuerdo con Perrotta y Podestá la fase III (donde habría piezas bicolores y tricolores) marca una transición que evidenciaría los comienzos de la influencia incaica, las fases $I V$ y $V$ (bicolores) corresponderían a momentos de influencia incaica, extendiéndose la fase $V$ hasta el Período Hispano Indígena. Podría decirse que el planteamiento de estas autoras es más rígido que el de Weber en cuanto a los límites entre las fases y la separación entre el universo bicolor y el tricolor, aunque reconocen que muchas veces resulta difícil la ubicación de ciertas piezas en alguna fase. En paralelo se realizó una seriación de los «pucos tapa» (cuencos) que acompañan a las urnas funerarias (Podestá y Perrotta 1973; Perrotta y Podestá 1974).

Nos interesa puntualizar que, más allá de los problemas o limitaciones que se hayan podido señalar en estos ensayos ${ }^{2}$, las seriaciones destacan un manejo particular de los colores -entre otras variables- en diferentes momentos del tiempo, siendo el tricolor característico de los inicios y el bicolor de la culminación de la tradición, pero muestran también, en especial el trabajo de Weber, que existen casos excepcionales que escapan a la generalización. Si bien las urnas y los pucos son las formas que predominan, no son las únicas. Una variedad de formas y tamaños de ollas, tinajas y pucos está aún a la espera de una descripción e integración a los modelos cronológicos. Por último hay que destacar que no se han publicado otros ejercicios de diferenciación de variantes con valor cronológico en los conjuntos santamarianos de otras regiones o tradiciones. Las tendencias de las variaciones a lo largo del tiempo de las urnas de la Tradición Yocavil (elongación del cuello, predominio del bicolor en momentos más tardíos sobre el tricolor, etc.) no deberían extrapolarse sin un análisis previo hacia las vasijas santamarianas de otras regiones, puesto que estas tendencias pueden ser sólo una expresión de los cambios estéticos en el área mencionada. De modo recíproco, no deberían criticarse los resultados de estos ejercicios con materiales de zonas que excedan la Tradición Yocavil.

\section{Método de estudio}

La muestra estudiada se compone de 22 vasijas que se identificaron observando cientos de piezas de las colecciones del Museo Etnográfico «Juan B. Ambrosetti», el Museo de La Plata, el Museo de la Universidad Nacional de Tucumán, el Museo

\footnotetext{
2 En distintos trabajos se ha puntualizado su carácter «atomizante» por desintegrar en el análisis la unidad constituida por una vasija, con resultados limitados a una morfología específica, con ambigüedades en el establecimiento del límite entre fases, con escasa consideración de la existencia de variantes individuales, familiares, grupales o microregionales invisibilizadas en las fases (Caviglia 1985; Nastri 1999; Velandia 2005; Palamarczuk 2011).
} 
Jesuítico de Tafí, el Museo Arqueológico «Juan Bautista Ambrosetti» de Quilmes y el Museo «Cóndor Huasi» de Belén, así como de la revisión de ilustraciones en la bibliografía.

Se propone una metodología que combina elementos basados en diferentes puntos de vista para el acercamiento al material. Por un lado se consideran los modelos de seriación para ubicar cronológicamente a las vasijas en base a sus características. Son aproximaciones que se fundamentan en la descomposición de la unidad que representan las vasijas de acuerdo con el aislamiento de las variables morfológicas, métricas y de diseño. El método divide las piezas en unidades sobre las cuales una visión de conjunto ha permitido notar variedad con el objetivo de encontrar una clave para ordenar el material en el tiempo. Es una segmentación analítica impuesta a los materiales de acuerdo con propósitos arqueológicos que no busca identificar aquellos elementos que hayan sido notables o significativos para los diferentes segmentos de la sociedad que los produjo.

Por otro lado trabajos como los de Jernigan (1986) y Caviglia $(1985,2002)$ muestran modos de abordar el estudio de los estilos decorativos que buscan explícitamente identificar con base en la observación de reiteraciones en las unidades de diseño y patrones de configuración o "esquemas» aquellos elementos significativos para las personas que elaboraron y usaron las vasijas u otros elementos decorados, destacando que el reconocimiento de esos elementos es indispensable para realizar comparaciones dentro de diferentes manifestaciones de un estilo o entre estilos diferentes. Pero dichos elementos no deben considerarse aisladamente, sino como parte de una totalidad que muestra sólo en su integridad (vasija completa) una lógica de diseño. Las clasificaciones de objetos basadas en estos métodos buscan revelar distinciones pretéritas. De acuerdo con esta postura, es posible reconocer las diferentes lógicas de diseño y de esa manera acercarse a los sistemas de transmisión de significados o mensajes inscritos en soportes como la cerámica, los textiles, los metales, el arte rupestre, la arquitectura, etc. En nuestro caso se busca, entonces, un acercamiento a las vasijas, poniendo el acento en la descripción de los esquemas vinculados a los modos de empleo de la pintura roja en las variantes Santa María «de tres colores» identificadas.

Se ha apuntado -y aquí coincidimos con ello- que la repetición de los diseños no es un indicador inequívoco de que estos hayan funcionado como unidades de significación, es a través de la comparación y posicionamiento en un contexto cultural, asociaciones de artefactos y procedencias que se puede avanzar en los significados de los esquemas (Douglas y Lindauer 1988). La noción de esquema es muy ilustrativa de una instancia de reconocimiento que es fundamental, la identificación de patrones, de aquello que se repite. La contextualización de esos patrones es una vía para indagar su significación.

Un método de trabajo que conjugue de manera consciente ambas perspectivas permite rescatar los resultados provechosos de ambas. Esta oposición, más que plantear una incompatibilidad, propone explorar las diferentes perspectivas en nuestra situación de observadores externos de la cultura santamariana, pero que buscan, quizás de manera utópica, superar esa condición limitada que impone la distancia temporal y cultural. 
Los estudios sobre la cronología del estilo santamariano de Yocavil, así como las críticas u observaciones a los mismos, constituyen tanto una base de supuestos como un punto de partida para la indagación en la cronología de cada pieza a evaluar. Así, se toman en cuenta los resultados de estos modelos, pero también la información que aportan otros trabajos quizás más puntuales o acotados a conjuntos cerámicos de una localidad específica o a una configuración de diseño o representación de un tema en particular. El trabajo con materiales de la colección Benjamín Muñíz Barreto del Museo de La Plata permitió reconstruir algunos contextos funerarios y, de esa manera, empleamos las asociaciones estilísticas para intentar la ubicación cronológica de algunas de las piezas. Para la mayoría de las vasijas, sin embargo, sólo se cuenta con información sobre la localidad de procedencia.

\section{Las variantes Santa María «de tres colores»}

A continuación se presentan las variantes identificadas a través de los 22 casos observados. Se describe cada ejemplar o conjunto de vasijas similares destacando los elementos relevantes para su ubicación cronológica. Se indican también los esquemas presentes en estas piezas en relación al empleo del color rojo. La información sobre procedencia, museo, colección y citas bibliográficas se resume en el Cuadro 1, mientras que el Cuadro 2 sintetiza la información sobre asociaciones contextuales en los 10 casos en los que dicha información estaba disponible.

\subsection{Variante banda roja vertical}

Esta variante se identificó en cuatro urnas. Como «urnas» santamarianas se conoce a un grupo morfológico de vasijas que podrían denominarse ollas con cuello o tinajas, de contorno compuesto o complejo, restringidas independientes (Shepard 1957), por la forma cerrada del cuerpo al que se suma el desarrollo de un ancho cuello que a veces es muy abierto. Tradicionalmente se ha denominado a este conjunto de formas como urnas, pues muchas de ellas se emplearon como contenedores en el entierro de párvulos, y así se las continuará llamando aquí, aun reconociendo que algunas de ellas han cumplido otros roles, como por ejemplo el acompañamiento funerario en entierros de adultos. También se reconocen otros usos no funerarios, tal como lo sugiere la abundancia de fragmentos en contextos domésticos.

Dentro de este conjunto se incluyen cuatro ejemplares $\left(\mathrm{N}^{\circ} 1\right.$ a 4 , Figura 1$)$ que conforman un subgrupo dentro de la variedad que Caviglia (1985) llamó Quilmes Reticulado. Estas urnas se clasifican como fase V (Perrotta y Podestá 1974; Weber 1978), los ejemplares conocidos son abundantes y proceden en su mayoría de Quilmes y El Bañado, donde hay extensos cementerios vinculados al gran poblado de Quilmes. Las cuatro urnas poseen baño blanco exterior completo y diseños en negro en las caras frontales con bandas laterales verticales con fondo rojo, superpuesto al baño blanco y dibujos negros sobre el fondo rojo. La banda, que posee un ancho variable entre tres y cinco centímetros y un largo equivalente a la altura de la vasija, está delimitada por líneas negras y contiene diseños en negro entre los que se reco- 


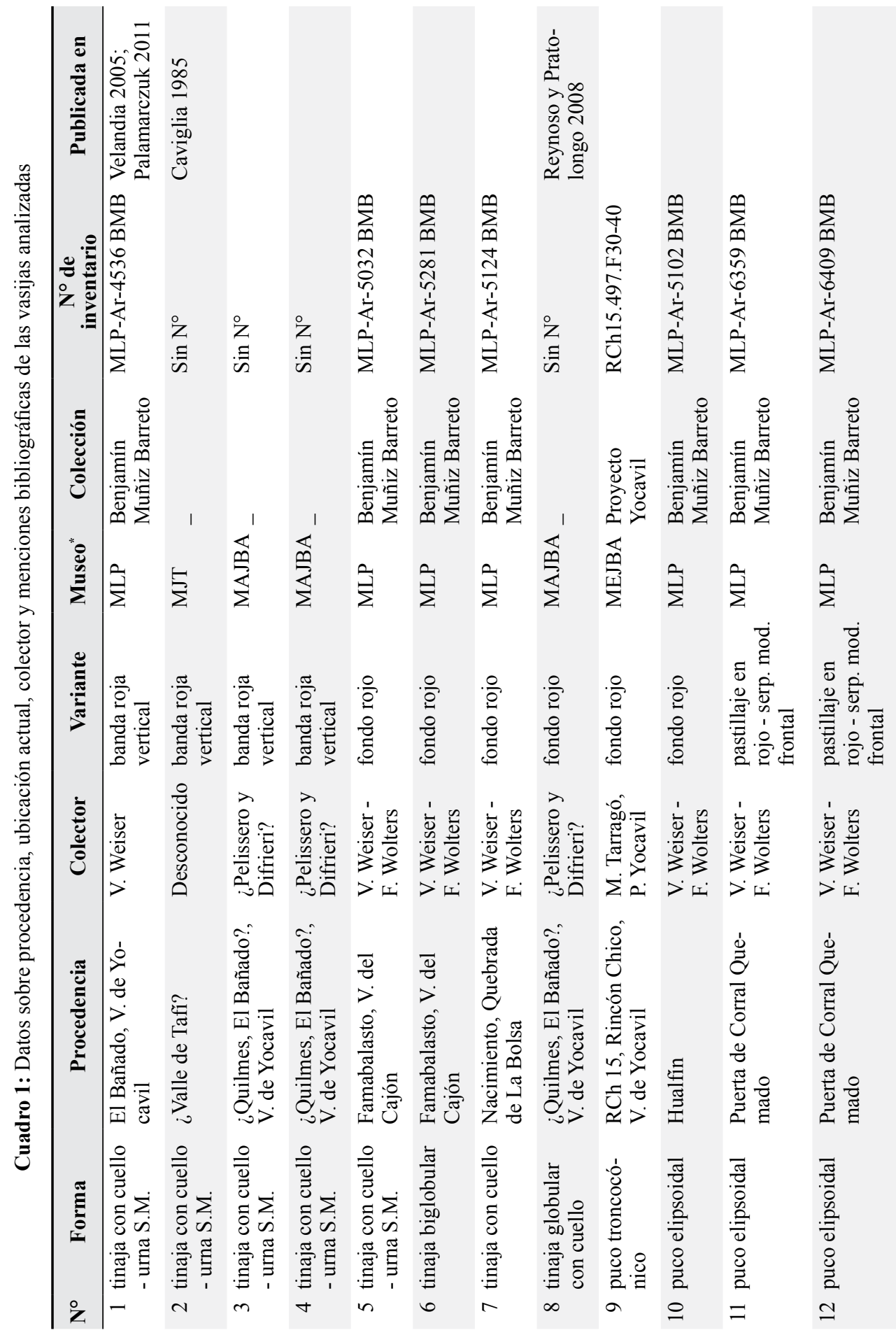




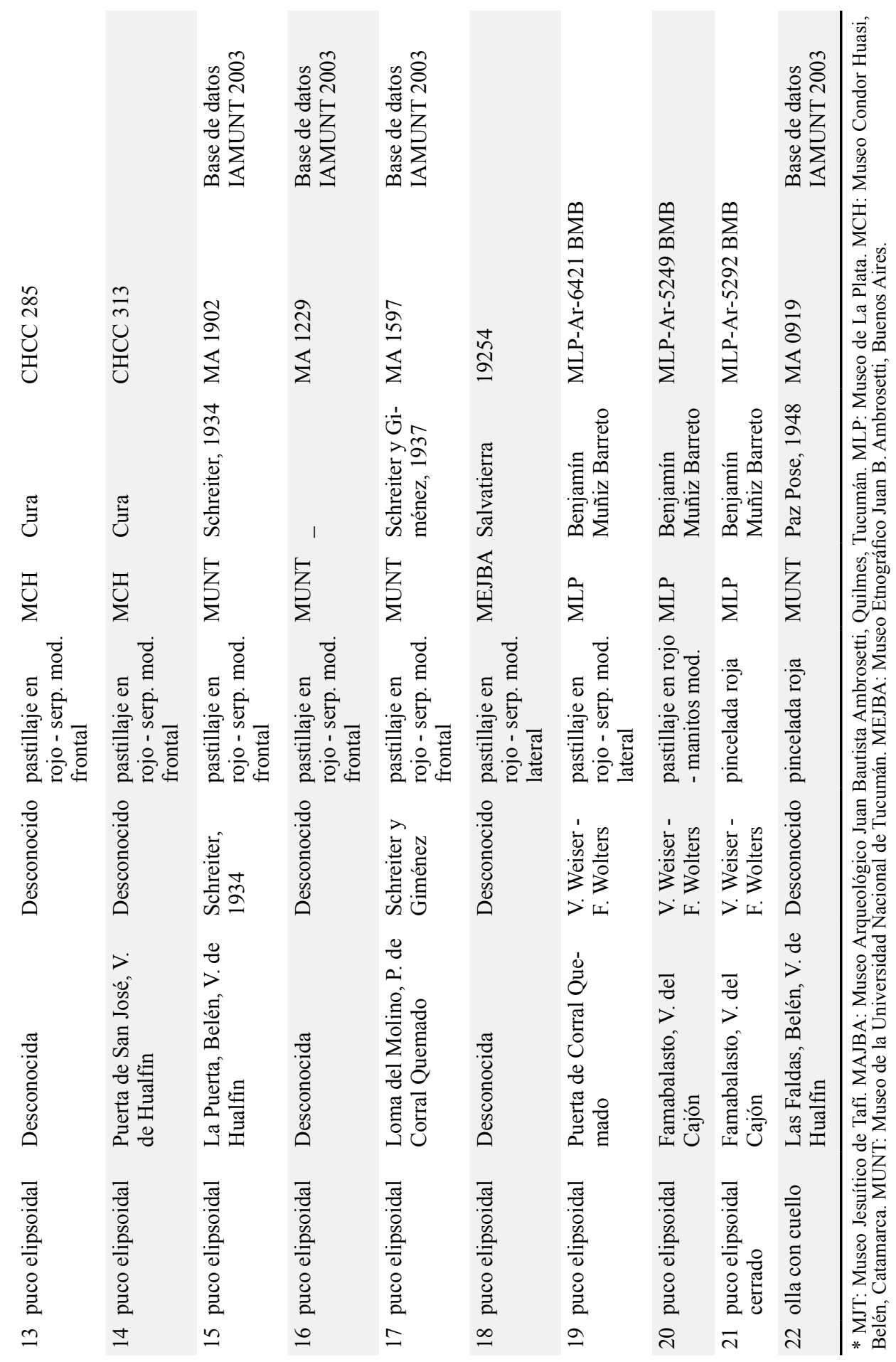




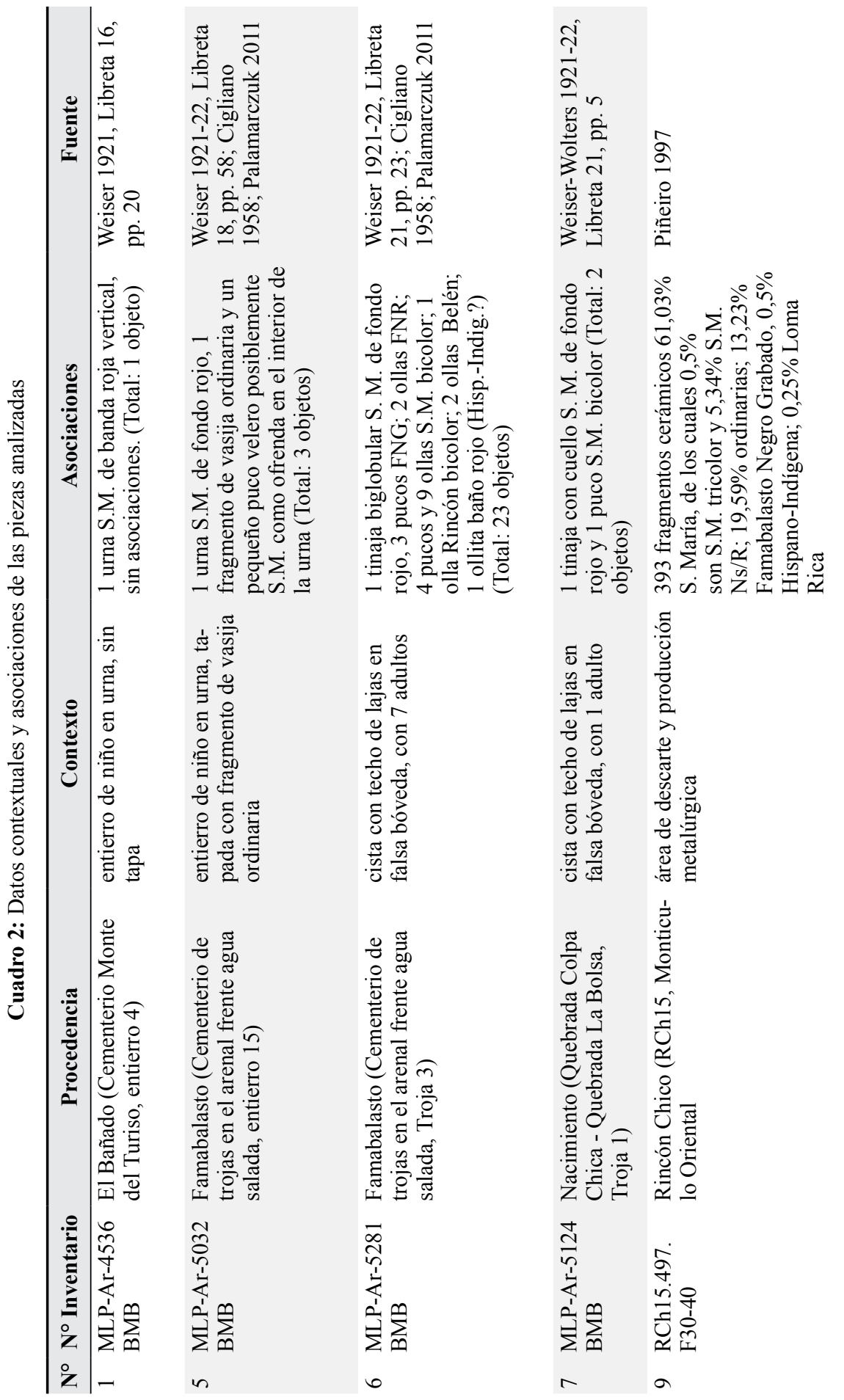




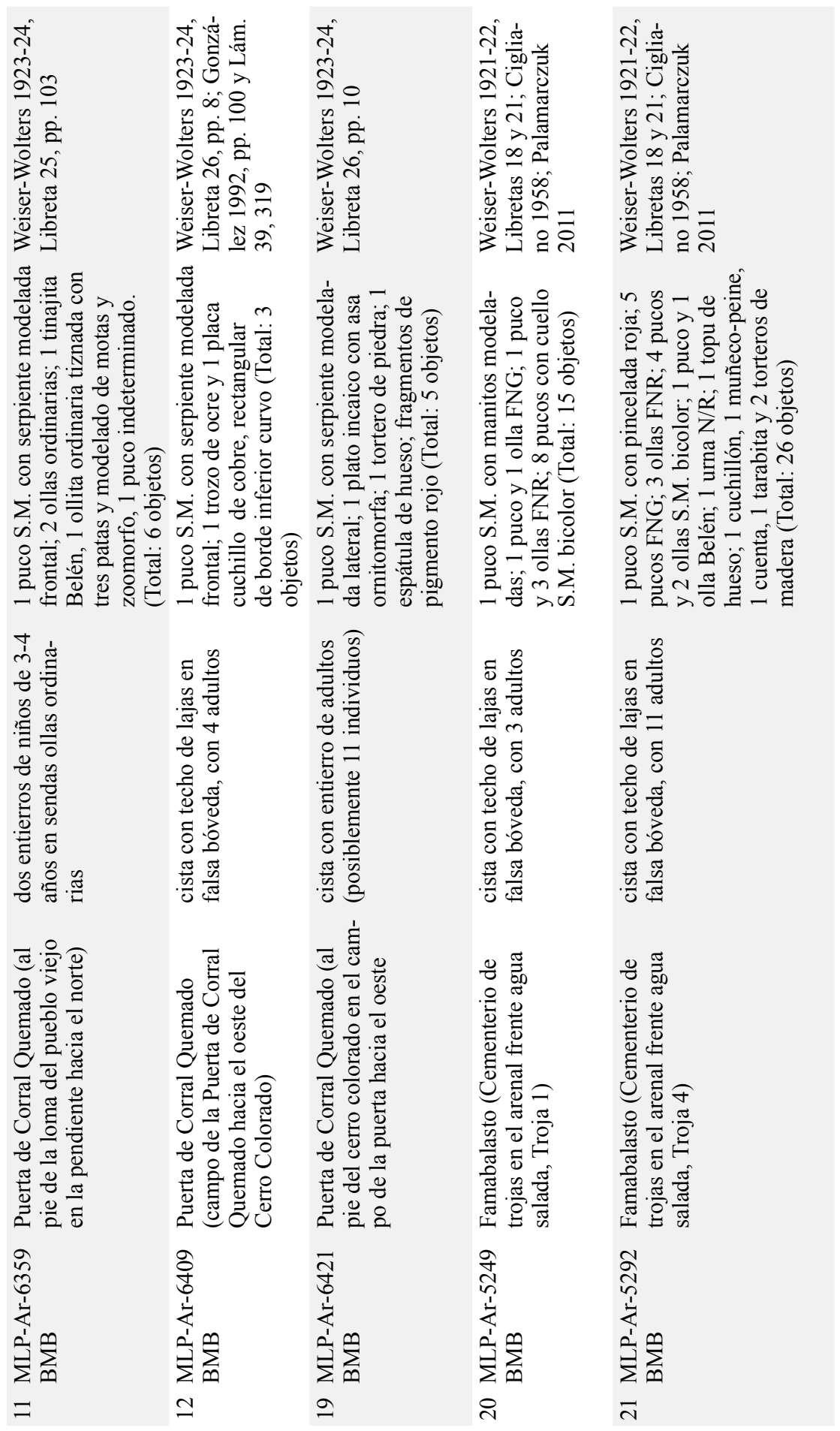



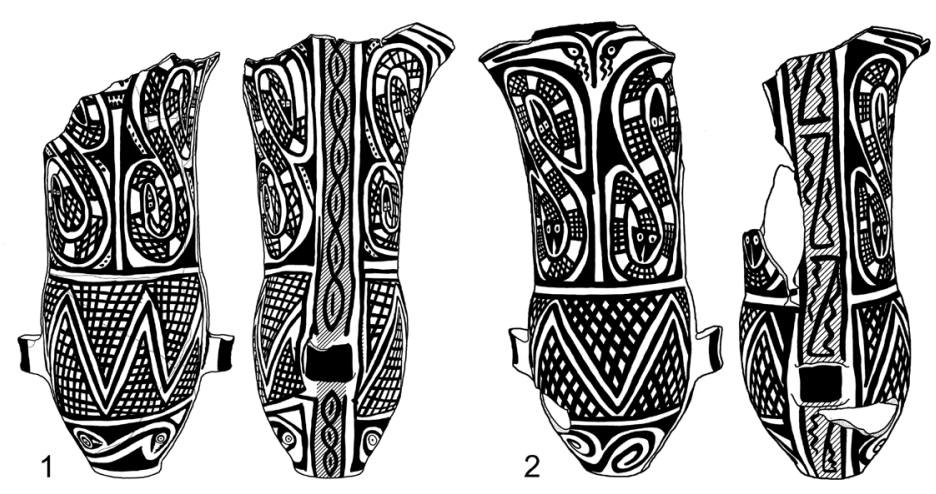

Figura 1: Ejemplares de la variante banda roja vertical.
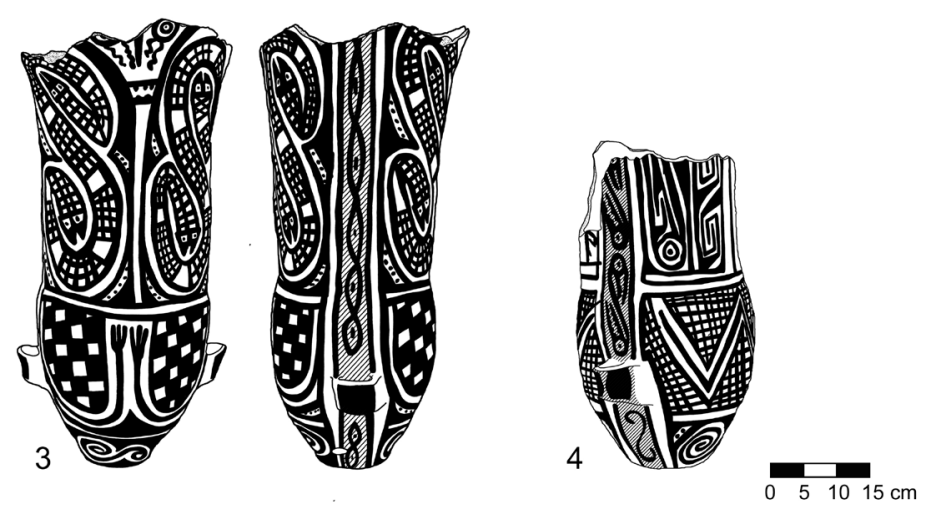

nocieron óvalos encadenados con rayita central (1 y 3), una sucesión vertical de un diseño que combina líneas ondulantes y rectas que forman una especie de Z (2) y una sucesión en sentido vertical de serpientes-suri bicéfalas con bocas dentadas «felinizadas», similares a las que se observan en uno de los lados de la cara frontal del cuello (Figura 1). Con respecto al primer diseño, vemos que se repite con insistencia en la alfarería Famabalasto Negro Grabado, como también en la metalurgia tardía del bronce (campanas y discos) (Palamarczuk 2011). El segundo diseño posee una larga historia y perduración en la alfarería santamariana de Yocavil, variantes del mismo se observan también en la cerámica Loma Rica y San José. En relación al tercer diseño interesa destacar que la «felinización» de ciertos elementos, como las serpientes-suri bicéfalas con fauces dentadas es un rasgo que se ha observado en los diseños pintados del santamariano más tardío (Reynoso y Pratolongo 2008). Con excepción de la $\mathrm{N}^{\circ} 2$, procedente de Tafí, las restantes son de la zona de Quilmes - El Bañado.

\subsection{Variante fondo rojo}

Esta variante se define por una manera particular de aplicación de la pintura roja, a modo de un baño que cubre una amplia extensión de cada vasija, pudiendo llegar al 
Figura 2: Ejemplares de la variante fondo rojo.
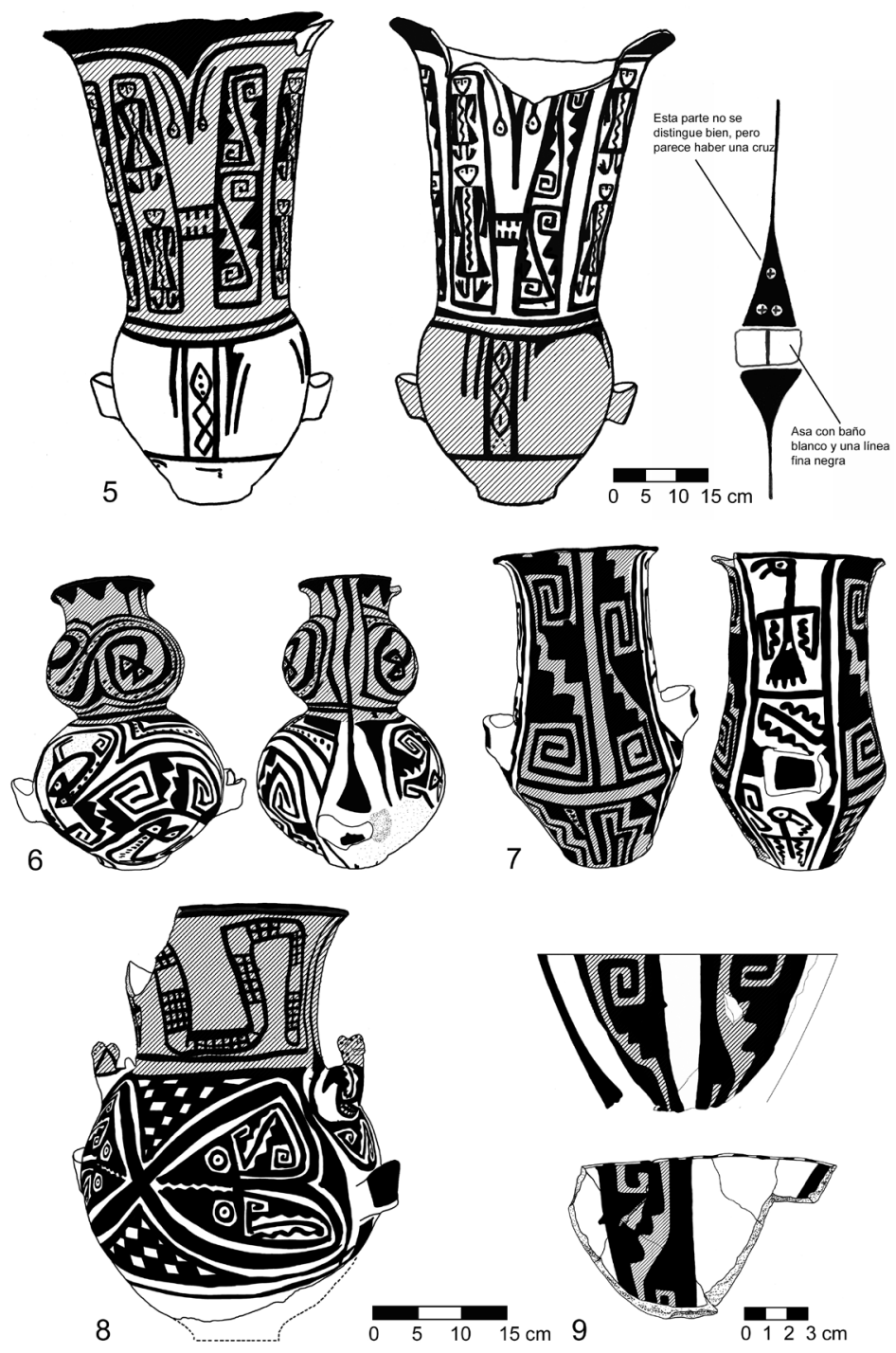

$50 \%$ del total de su superficie. Allí la secuencia de aplicación de los colores comienza con el baño blanco que cubre sólo los sectores que se ven de este color, luego el baño rojo, que puede superponerse a la pintura blanca sólo en las zonas de límite entre ambos colores y luego los dibujos en negro en toda la pieza ( $\mathrm{N}^{\circ} 5$ a 10). Las piezas corresponden a morfologías diversas que, en algunos casos como el 6 y el 7 , podemos catalogar como rarezas. Un diseño que se repite son los escalonados plenos con greca en disposición vertical (Figura 2).

La urna 5, procedente de Famabalasto, al sur del valle del Cajón, tiene sus superficies muy deterioradas, a pesar de lo cual pudimos reconstruir parcialmente sus 
diseños. Por encima del baño tiene diseños en pintura negra, con representación del «ídolo de las cejas» en el cuello. En cada mejilla se delimitaron dos campos rectangulares alargados, en cada uno de estos espacios se suceden verticalmente dos escalonados plenos con greca y en el otro dos «guerreros». En las dos mejillas y en ambas caras de la urna se repiten las mismas tiras de acuerdo con una secuencia de izquierda a derecha de grecas-guerreros. La decoración en el cuerpo es muy poco visible pero se llega a notar una franja vertical central formada por rombos encadenados con rayita o puntos centrales. La banda lateral que pasa a la altura de las asas forma un diseño en negativo que parece figurar una cabeza humana triangular invertida.

Los guerreros en los cuellos de las urnas son un rasgo típico de las urnas fase $I V$, aunque no conocemos otro ejemplar con una combinación similar de franjas verticales y guerreros. Parámetros como el ángulo del cuello, los índices altura del cuello/ diámetro mínimo del cuello y altura del cuello/altura del cuerpo y la forma elipsoidal del cuerpo, colocan a esta vasija en una situación intermedia entre las fases $I V$ y $V$. Nótense las diferencias de esta urna en relación al conjunto Quilmes Reticulado por ejemplo en la ausencia de lágrimas, diferente patrón de configuración de diseños y diferente contorno, con marcada separación entre cuello y cuerpo.

La pieza 6, también de Famabalasto, presenta una forma similar a una calabaza, con dos segmentos globulares, más grande el inferior que el superior. El segmento inferior posee baño crema, mientras que el superior está cubierto por un baño rojo. El baño rojo cubre también la superficie interior del cuello, donde se pintaron líneas perpendiculares de color negro (decoración que observamos en algunas urnas Belén y Santa María Negro sobre Rojo). En la superficie exterior el diseño se divide en dos grandes campos de lectura plana, que a su vez se divide en el plano vertical en tres segmentos: cuello, parte superior y parte inferior del cuerpo. En el cuello se diseñó una guarda de triángulos negros plenos, en el glóbulo superior hay serpientes bicéfalas en «S» horizontal, en el inferior se repite el tema de la serpiente bicéfala enroscada, pero esta vez el cuerpo está formado por una gruesa tira de triángulos escalonados con greca. Ciertos elementos de diseño en este ejemplar se han observado en piezas consideradas muy tardías. La guarda de triángulos plenos en el cuello está presente en aribaloides y urnas piriformes. Su contexto de hallazgo es un entierro múltiple de siete individuos, con evidencias de reaperturas para el ingreso de nuevos cuerpos y ofrendas, por lo que el nivel de asociación entre las ofrendas es relativo. No obstante las otras 22 vasijas que integran el contexto, corresponden a estilos asimilables al Tardío final - Inca - Hispano Indígena (ver Cuadro 2).

La tinaja 7 fue hallada en la Quebrada Colpa Chica o Quebrada de La Bolsa, Nacimiento en asociación con un puco Santa María bicolor, ambas como ofrendas en un entierro individual. Posee baño crema y rojo que fue aplicado formando cuatro franjas verticales alternadas; las laterales, que pasan a la altura de las asas, tienen un fondo crema, mientras que ambas caras frontales tienen fondo rojo. La parte interior del cuello posee también pintura roja y una decoración en pintura negra que consiste en una sucesión de líneas perpendiculares, similares a la guarda del borde interno de la anterior pieza biglobular. En las caras frontales el campo decorativo se divide en un segmento superior, formado por el cuello y un segmento inferior que ocupa el cuer- 
po. En el segmento superior se dibujaron dos tiras verticales paralelas con triángulos escalonados y grecas. A los costados se representa en forma vertical un ave con una o dos cabezas, serpiente «con rulos» y diseños en forma de «S» vertical. El motivo del ave con dos cabezas se observa en aribaloides de época inca y urnas santamarianas del extremo final de la serie.

La olla 8 fue hallada en la zona de Quilmes, posee un cuerpo globular con baño blanco y un cuello con baño rojo. El diseño, en pintura negra, se organiza de acuerdo a una lectura plana en dos grandes campos frontales que se dividen en un segmento superior (cuello) y uno inferior (cuerpo). En cada cara del cuello se dibujó una gran serpiente con cuerpo «almenado» dividido en segmentos reticulados que recuerda simultáneamente a los almenados presentes en los cuellos de las urnas Belén y también a las serpientes presentes en las «mejillas» de las urnas Quilmes Reticulado. En los campos del cuerpo hay un diseño poco común que conjuga en un mismo motivo el tema de la serpiente bicéfala con el de la serpiente con dos cuerpos y una cabeza, formando un cuerpo doble que se cruza describiendo una $X$, con dameros ocupando los espacios libres. Las serpientes poseen boca dentada y unos tocados o «cabellera» con diseño de greca y triángulo escalonado, un diseño similar al que se pintó sobre el cuerpo de los felinos modelados sobre las asas. La representación de "cabellera» en las serpientes, formada por líneas onduladas, grecas o espirales es un rasgo que se observa en algunos ejemplares del Santa María Tricolor temprano, sin embargo representaciones más exageradas, con rulos más largos y mayor cantidad de variantes en su diseño son propios del santamariano más tardío, al igual que la «felinización» de temas zoomorfos pintados y el aditamento de felinos modelados, como los que se aplicaron por encima de las asas (Reynoso y Pratolongo 2008).

El puco 9 procede de la localidad de Rincón Chico, sitio RCh 15, Montículo Oriental, un sector interpretado como un complejo de basural y área de producción metalúrgica. Este raro ejemplar de puco troncocónico se reconstruyó parcialmente a partir de varios fragmentos remontados. Posee un baño crema en la cara externa, sobre la que se trazaron una serie de bandas verticales en pintura negra formadas por triángulos escalonados plenos con greca y delimitadas por líneas verticales subparalelas. El fondo de los campos de las guardas está pintado en color rojo. Sobre el labio, recto, se pintaron rayitas negras. En la superficie interna se pintaron también las mismas bandas sobre un baño blancuzco, menos espeso que el de la superficie externa. La clasificación cronológica tardía para este cuenco se plantea aquí en función de la comparación con los casos enumerados arriba $(5,6,7$ y 8$)$ que muestran en diferentes disposiciones el mismo elemento de diseño que aquí conforma las guardas verticales, y que en algunos casos como el ( 5 y 7) tienen también una disposición vertical y un fondo rojo. Asimismo, las rayitas negras sobre el labio son características de los $p u$ cos Santa María más modernos.

El puco 10 (Figura 3) procede de Hualfín. Ambas superficies poseen medio baño blanco y medio rojo y diseños negros similares. Las mitades blancas tienen un animal mixto llama-felinizada y las rojas, serpientes bicéfalas. La superficie interna muestra desgaste en el fondo compatible con un uso previo al funerario.

La dispersión de esta variante involucra espacios del centro y sur de Yocavil, sur del valle del Cajón y norte del valle de Hualfín. 

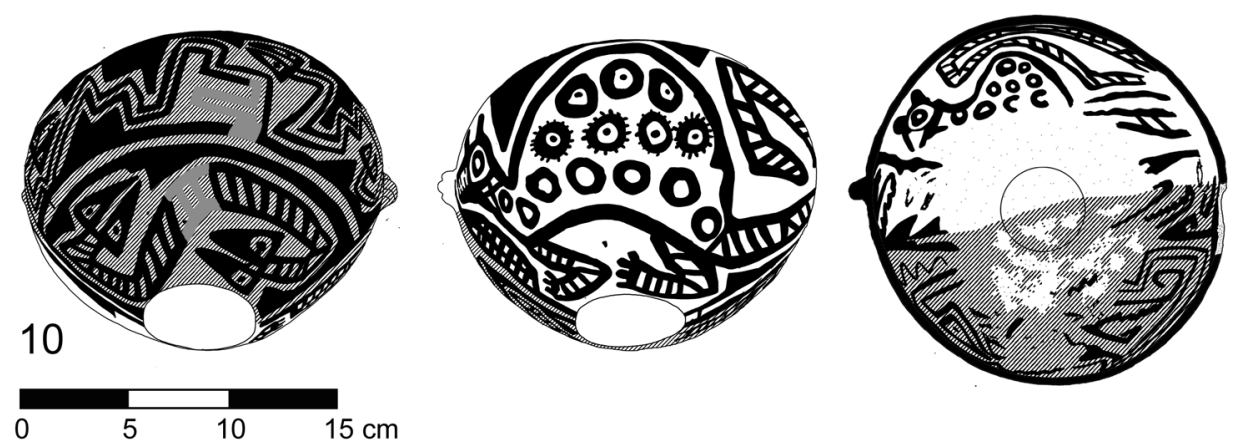

Figura 3: Ejemplar de la variante fondo rojo.

\subsection{Variante pastillaje en rojo}

En este grupo incluimos diez pucos o cuencos que poseen aplicaciones al pastillaje elongadas, describiendo formas sinuosas en su parte superior (por encima del punto de tangencia vertical) y en contacto con el labio de la vasija, estas aplicaciones han sido pintadas de rojo, siendo el resto de la superficie exterior negro sobre blanco. De cuerpo elipsoidal, borde entrante y labio recto, sobre el cual se pintaron rayitas negras, un esquema que se repite en los pucos Santa María más tardíos. La superficie interna puede tener baño rojo o bien un alisado, con diseños pintados o salpicaduras. De acuerdo con la figura modelada distinguimos tres grupos:

\subsubsection{Serpiente modelada frontal}

Las piezas 11 a 17 poseen dos serpientes bicéfalas de cuerpo ondulante que se despliegan sobre las caras frontales del puco (Figura 4). Las cabecitas redondeadas, con ojos y boca incisos, miran hacia arriba y se juntan con las de la serpiente opuesta en la zona donde se encuentra la divisoria lateral de los dos grandes campos de diseño, sobresaliendo del labio. Los cuerpos modelados de las serpientes están delineados en sus contornos con pintura negra y pueden tener el cuerpo moteado. En general observamos que están pintadas de rojo con una pintura muy desleída, que se ha desprendido en varios sectores. Ésta es una característica que comparten varios de estos pucos: una mala adherencia del baño y las pinturas en las superficies. Cada campo posee un división horizontal y se reitera el motivo de greca o gancho con escalonados plenos. La pieza 11 tiene su superficie interna muy desgastada. La 13 se destaca por el diseño de una cabeza triangular invertida, posiblemente humana, a cada lado, por debajo de las cabecitas de serpientes, ocupando el lugar de la divisoria de campos. Por su ubicación y posición invertida recuerdan a las cabezas observadas en la pieza 5 de esta muestra y en otras urnas santamarianas tardías en las que las cabezas invertidas evocan la práctica de las cabezas trofeo (Nastri 1999). Este diseño, al presentarse en piezas muy tardías, contribuye a la ubicación temporal de estos pucos. Los casos 15, 16 y 17 se registraron en base al catálogo del IAMUNT y sus diseños se observaron parcialmente. 

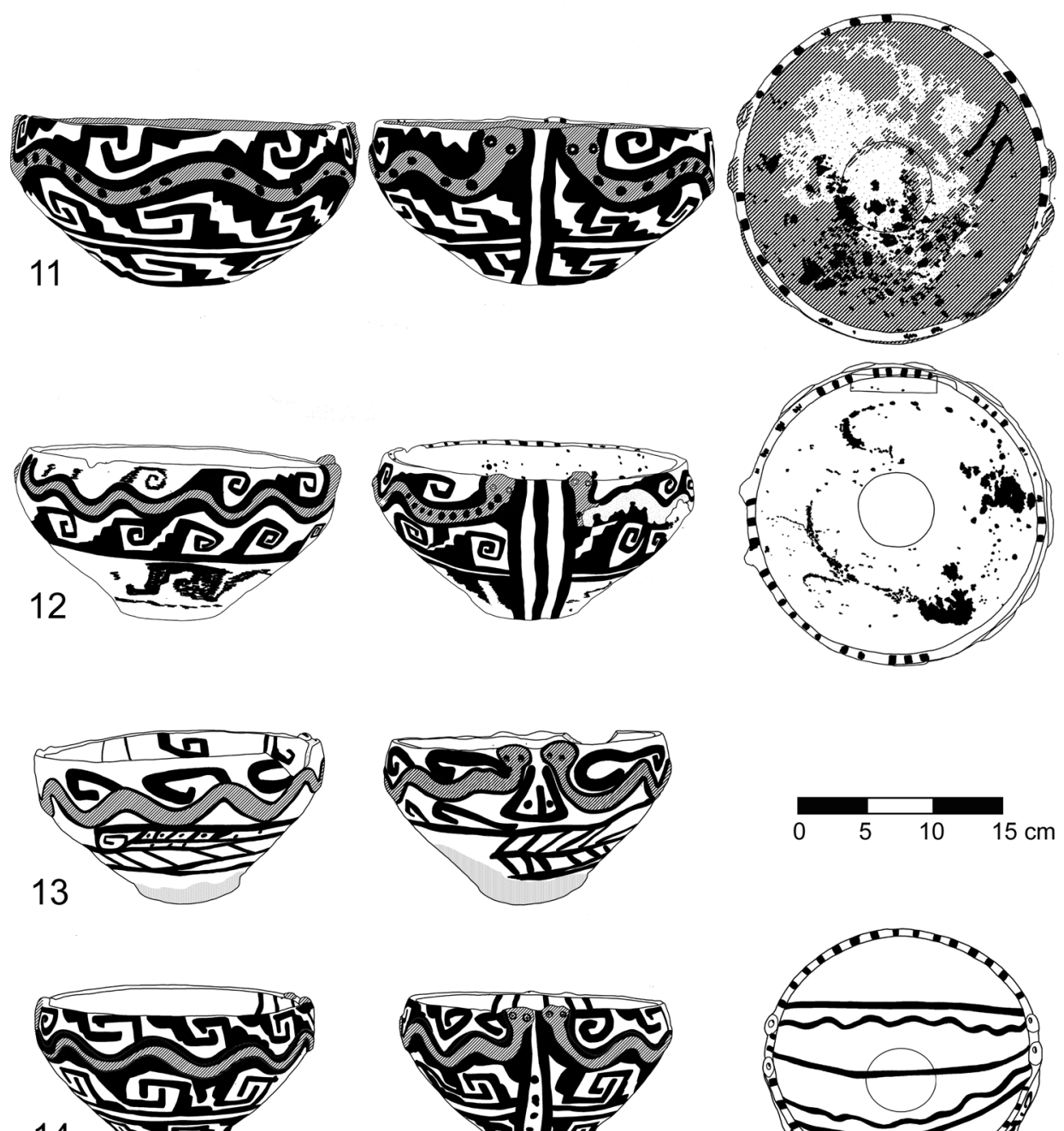

14
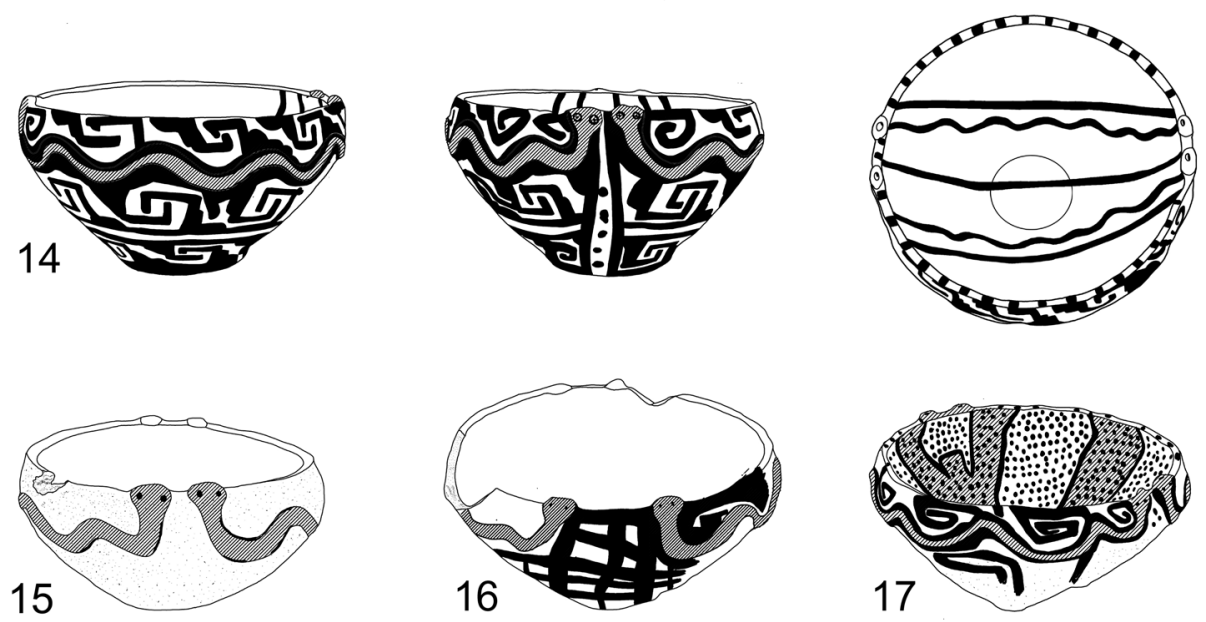

Figura 4: Ejemplares de la variante pastillaje en rojo, serpiente modelada frontal. 


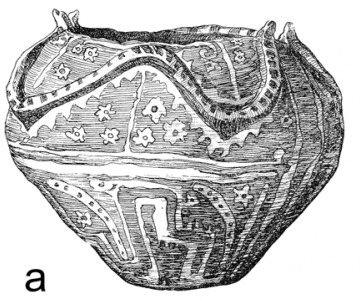

a
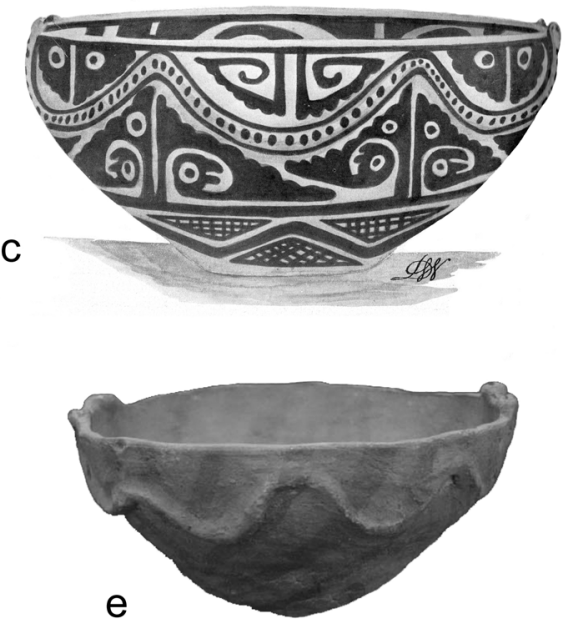

$\square \square$

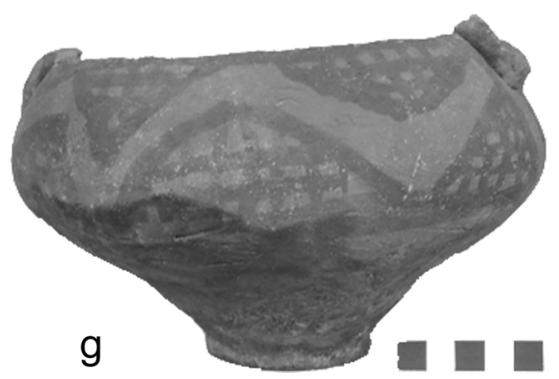

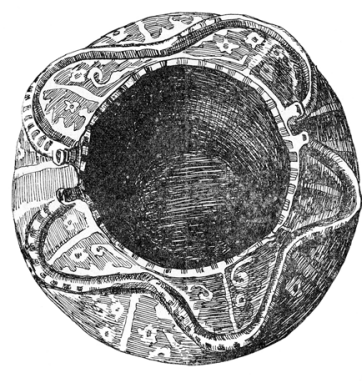

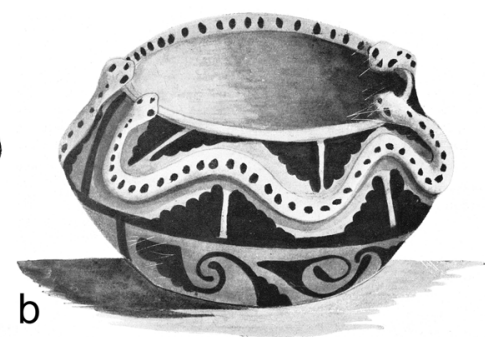

$\mathrm{d}$
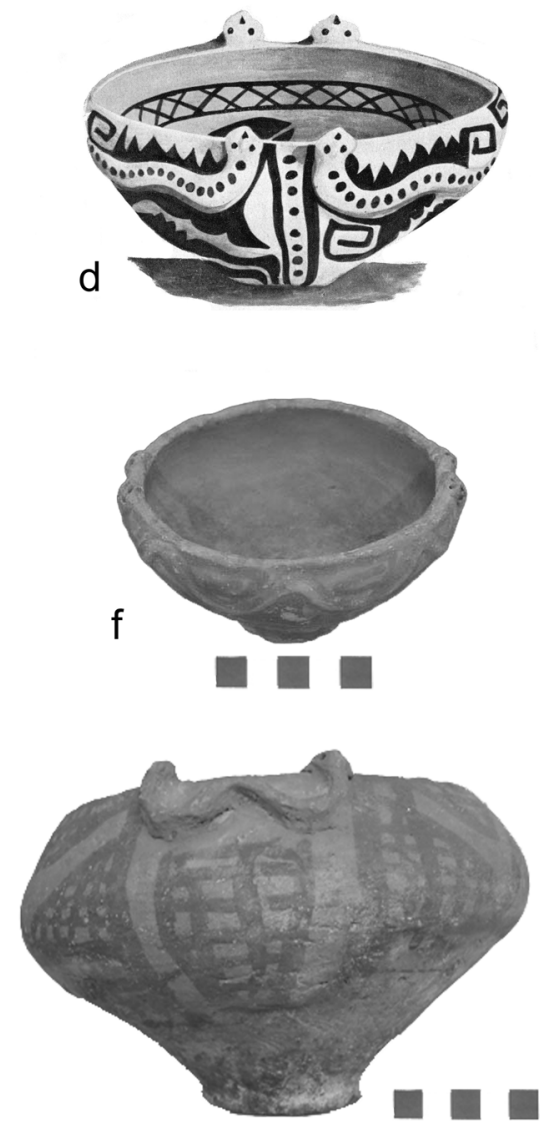

Figura 5: Diversidad de ejemplares con serpientes modeladas: a) MLP-Ar-5331 BMB, procedencia Famabalasto (Cigliano 1958: 94-95, Fig. 20 y 21); b) MEJBA -25692-, Col. Zavaleta, procedencia indeterminada; c) MEJBA -25443-, Col. Zavaleta, procedencia Molinos; d) procedencia Catamarca (Wagner y Wagner 1934: 269-270; Fig. 458, 459 y 460); e) MA 2200, Col. Paz Posse 1948, procedencia El Campito, Corral Quemado, Belén (Base de datos IAMUNT 2003); f) MA 1003 (Base de datos IAMUNT 2003); g) MLP-Ar-5105 BMB, procedencia Baudillo, Hualfín. 
Los cinco casos con procedencia conocida son de la zona de Hualfín; Puerta de Corral Quemado, Puerta de San José y La Puerta, Belén, por lo que planteamos que se trata de una variante santamariana propia de esta zona. Al respecto es interesante notar que existen otros pucos con serpiente modelada lateral con características diferenciables, por ejemplo los pucos pintados en negro sobre rojo que conjugan características de los estilos Santa María y Belén (Figura $5 \mathrm{e}, \mathrm{f}$ y g). Por último hay un grupo de pucos negro sobre blanco como el de la Figura 5a. Este puco, hallado en Famabalasto, tiene una forma más cerrada y sus diseños pintados son del tipo que Serrano (1958) llamó Valle Arriba. Wagner y Wagner (1934) ilustran tres pucos bicolores, dos de ellos (Figura $5 \mathrm{~b}$ y c) con decoración de tipo Valle Arriba que en la actualidad se conservan en el Museo Etnográfico «Juan B. Ambrosetti», el N ${ }^{\circ} 25692$ de procedencia desconocida y el $\mathrm{N}^{\circ} 25443$ de Molinos, Salta. Estas vasijas corresponden a una modalidad propia del Valle Calchaquí ${ }^{3}$. Vemos entonces que las serpientes modeladas frontales aparecen integradas a diferentes modalidades decorativas regionales, siendo la variante con pintura roja frecuente en la zona de Hualfín.

\subsubsection{Serpiente modelada lateral}

Los pucos 18 y 19 tienen sendas serpientes bicéfalas aplicadas al pastillaje, ubicadas en los laterales del cuenco y repasadas con pintura roja (Figura 6). Al igual que en los modelos mencionados arriba, las cabecitas sobresalen del labio (pintado con rayitas) $\mathrm{y}$ tienen boca y ojos incisos. En el caso 18 las serpientes tienen una curva en el cuerpo, en forma de «W» $»^{4}$. En ambas superficies se dibujaron dos serpientes bicéfalas y la superficie interior está muy desgastada por uso. En el $\mathrm{N}^{\circ} 19$ las serpientes tienen la forma de una «U», el interior está decorado con salpicaduras y el exterior con serpientes bicéfalas y ganchos con escalonado pleno. Este ejemplar procede de Puerta de Corral Quemado y fue hallado como ofrenda en una cista con entierros múltiples (posiblemente de once individuos adultos) junto con un plato incaico con asa ornitomorfa (ver Cuadro 2).

\subsubsection{Manitos ${ }^{5}$ modeladas}

El puco 20 tiene aplicaciones similares por su forma en «U» a las del 19 pero, en este caso, los extremos tienen forma de manitos con dedos incisos (Figura 6). Los diseños están muy borrados y cubiertos parcialmente por una capa de hollín. Se distinguen diseños de greca y escalonado pleno. En la superficie interna presenta salpicaduras en pintura negra y roja. El labio tiene diseño de rayitas. Fue hallado en Famabalasto, en una cista con tres adultos donde las ofrendas cerámicas corresponden a estilos Famabalasto Negro Grabado, Famabalasto Negro sobre Rojo y Santa María bicolor.

\footnotetext{
3 Hay que destacar que, si bien el puco MLP-Ar- 5331 BMB fue hallado en una tumba en la localidad de Famabalasto, al sur del Valle del Cajón, es altamente probable que se trate de una vasija alóctona, ya que es la única con esa clase de decoración recuperada en los contextos funerarios de la zona.

4 Nótese la semejanza con el modelado de la serpiente en el puco negro sobre rojo de la Figura $5 \mathrm{~g}$.

5 Se usa aquí «manito» como diminutivo de «mano», que es lo habitual en la mayor parte de América, en lugar de «manita», la forma habitual en España y en México (véase el Diccionario panhispánico de dudas de la Real Academia Española). (N. del E.).
} 

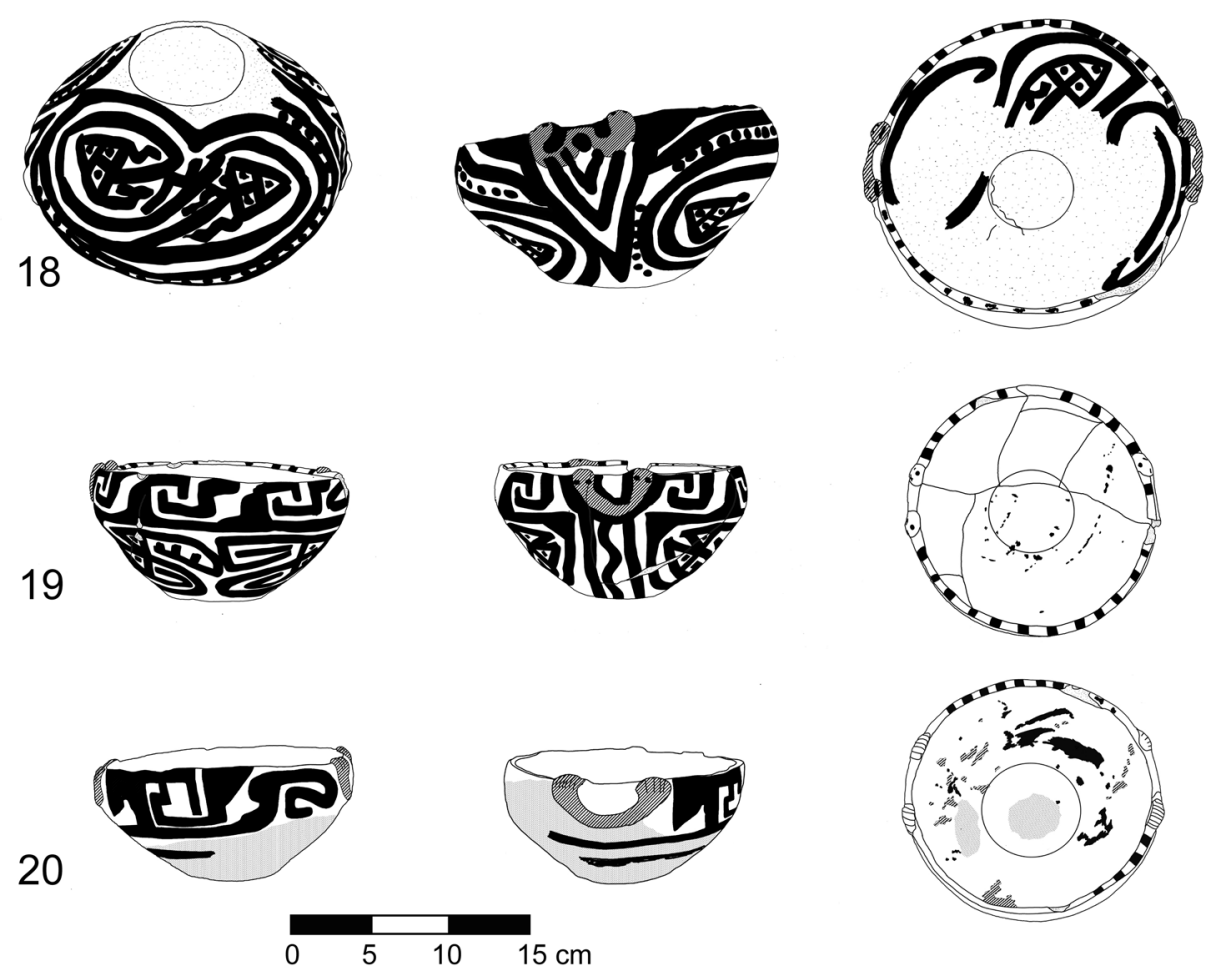

Figura 6: Ejemplares de la variante pastillaje en rojo, serpiente modelada lateral y manitos modeladas.

\subsection{Variante pincelada roja}

Otros usos aislados de la pintura roja se observan en el puco 21 (pincelada roja por encima del diseño en negro) y en la olla 22 (sucesión de puntos rojos) (Figura 7). Tentativamente se llamará a estos modos de aplicación «Variante de pincelada roja». El $\mathrm{N}^{\circ} 21$ es un pequeño «vaso del parto». Una línea negra horizontal ubicada debajo del punto de tangencia vertical define dos campos de lectura continua. La banda superior está formada por grecas con triángulos plenos y la inferior por un zigzag de cordón punteado que culmina en una cabeza de serpiente. La pintura roja fue aplicada con un trazo grosero superpuesto al trazo negro en un sector de la guarda superior, inclusive en sectores del labio, que está cubierto por una línea negra continua. Fue hallado en Famabalasto, en una cista con once individuos junto con alfarería Famabalasto Negro Grabado, Famabalasto Negro sobre Rojo, Santa María bicolor, Belén y una urna negro sobre rojo (Belén-Santa María) (ver Cuadro 2).

La pieza 22 es una olla con cuello. Los diseños se disponen en un gran campo que involucra a la sección media del cuerpo y al cuello. En esta zona se dibujó con pintura negra una gran serpiente con quiebres angulosos en un cuerpo dividido por rayas paralelas oblicuas rellenas por puntos negros y rojos. Los espacios delimita- 

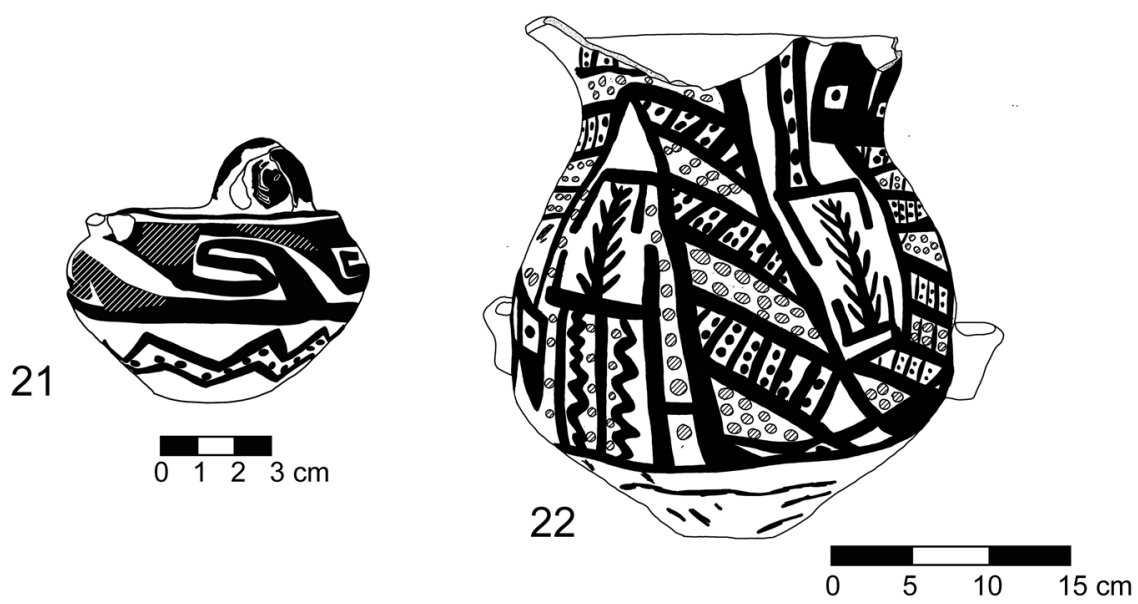

Figura 7: Ejemplares de la variante pincelada roja.

dos por el cuerpo de la serpiente fueron rellenados con diseños verticales en pintura negra, entre los que se destaca una posible variante del «helecho» incaico. En esta pieza se conjugan elementos de estilos Belén, Santa María e Inca. Sus relaciones de proporción se asemejan a las vasijas hispano-indígenas de Cachi Adentro (Tarragó 1984) y de Caspinchango (Debenedetti 1921), pero el punto angular que demarca la sección inferior del cuerpo está presente en tinajas Belén, en las que también abundan las serpientes con segmentación oblicua del cuerpo. La suma de los atributos de esta vasija «híbrida» apunta a una cronología muy tardía, posiblemente de época colonial temprana; fue hallada en Las Faldas, Belén.

\section{Comparaciones, síntesis y comentarios finales}

Con estas descripciones de variantes Santa María «de tres colores» en mente realizaremos una comparación con el Santa María tricolor clásico para destacar puntos en común y contrastes que faciliten su distinción en conjuntos fragmentarios. Uno de los elementos de contraste es el de la tonalidad de los pigmentos; el Santa María tricolor posee diferentes tonalidades de color rojo que van desde un rojo intenso hasta un burdeos, o «borra de vino» que posiblemente sea la tonalidad de rojo predominante en Yocavil. Por su parte las variantes Santa María «de tres colores» poseen en todos los casos un tono de rojo intenso: 10R 4/8 y 4/6 (rojo) de acuerdo con la carta de colores Munsell.

Con respecto a los modos de aplicación del pigmento rojo en el Santa María tricolor, éste se presenta generalmente acotado y cubriendo una proporción menor de la superficie total de las piezas en relación a los colores blanco y negro. Se encuentra también superpuesto al baño blanco y, con excepción de los casos en los que cubre 

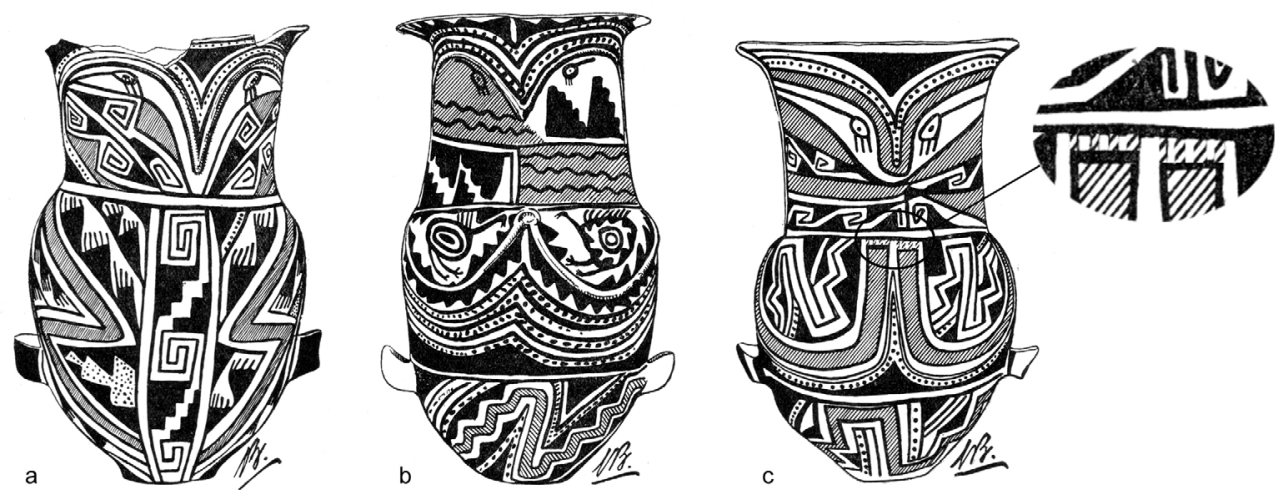

Figura 8: Distintos modos de aplicación del pigmento rojo en vasijas Santa María tricolor; a, b y c: procedencia Quilmes. Imágenes modificadas de Bruch (1911: 37, Figs. 33, 35 y 34 respectivamente).

espacios más amplios, suele ser la última aplicación de pigmento en la confección de la vasija. Predomina un empleo de la pintura roja llenando espacios estrechos y geométricos (triángulos, cuadrados, rectángulos, óvalos) o lineales (escalonados, «S», cuerpos de serpientes, suris o ñandúes u otros elementos zoomorfos) delimitados por líneas de pintura negra (Figura 8a); este modo de aplicación de la pintura roja no se ha observado en las variantes más tardías descritas. También podemos ver la pintura roja llenando espacios más amplios, como los campos alternos de las mejillas en los cuellos de las urnas. En estos casos la superficie pintada de rojo es más dilatada y puede contener dibujos en pintura negra (Figura 8b). Este modo de aplicación del pigmento rojo presenta puntos de contacto con el descrito para las variantes banda roja vertical y fondo rojo y puede llegar a confundirse al analizar fragmentos, por lo que, en el caso de que la conservación de los fragmentos lo permitan, deberán considerarse aspectos como los motivos presentes, la tonalidad del pigmento rojo, las características del campo pintado de rojo (orientación, sector de la vasija en el que se ubica), la forma de la vasija y el tipo de pasta ${ }^{6}$. Otra manera de aplicación muy poco frecuente en el Santa María tricolor es el trazo de diseños con líneas rojas finas, no delimitadas por líneas negras (Figura 8c), nuevamente, es necesario en los casos en que se identifique este tipo de trazos en fragmentos, utilizar otros elementos de distinción para discriminarlos de la variante pincelada roja.

En relación a los motivos recurrentes en las variantes «de tres colores», llama la atención la presencia reiterada de guardas con disposición vertical en las variantes banda roja vertical y fondo rojo. Podemos ver en estas bandas una reiteración de motivos similares como el triángulo escalonado con greca. Estos motivos son básicos del estilo Santa María y los vemos también en el Santa María tricolor, aunque en ese caso sólo pudimos observarlo dibujado en negro sobre el fondo crema o también con el interior de los triángulos pintado de rojo, pero nunca de la manera en que aparece

6 Las diferencias en el plano tecnológico como la composición de los pigmentos y los tipos de pastas cerámicas aún no han sido indagadas, pero son potenciales variables para la discriminación de variantes. 
en las variantes «de tres colores» más tardías (dibujos negros sobre fondo rojo). Otro motivo recurrente son los óvalos encadenados con rayita central. Por otra parte hay una variedad de elementos geométricos, zoomorfos y antropomorfos en estas bandas. Ya destacamos un elemento en común a todas ellas que es su disposición vertical. Otros esquemas son el movimiento de traslación vertical de las unidades de diseño y la repetición de sólo una unidad (no hay en ninguna banda dos unidades de diseño diferentes, siempre se repite la misma).

Con respecto a la variante pastillaje en rojo, vemos que los pucos con serpiente modelada pueden corresponder a una variante del área de Belén. Este dato apoya la definición de las manifestaciones santamarianas de esta zona, escasamente consideradas en los estudios del estilo Santa María.

En síntesis, las variantes «de tres colores» descritas pueden revelar procesos de diferenciación local del estilo Santa María, pero que simultáneamente están acompañando fenómenos de variación generalizados a nivel regional (tendencia a la elongación de los cuellos y ausencia de pastillaje en las urnas, decoración del labio con rayitas en los pucos, entre otras). Hemos registrado además vasijas de varias localidades de Yocavil y aledaños, lo que nos muestra que el desarrollo de variantes «de tres colores» tardías fue un fenómeno estilístico regional, aunque numéricamente acotado. Su desarrollo se ubicaría en los momentos muy tardíos cercanos a la expansión incaica y posteriormente a la invasión europea. Por lo tanto nos remite a escenarios sociales múltiples y en continua redefinición. Circunstancias diferentes que, por razones que deben analizarse puntualmente en cada caso, acompañaron e influyeron en el surgimiento de una variedad estilística, ya sea por desarrollo de variantes al interior de los estilos locales, por ejemplo las urnas Negro sobre Rojo o Belén - Santa María y Quilmes, variantes en las ollas peinadas con asas verticales, con pie de compotera, etc., así como por circulación de «nuevos» estilos contemporáneos en la región, por ejemplo el Yocavil, Yavi, Famabalasto Negro sobre Rojo, diversos estilos incaicos, Caspinchango, etc. Este notable desarrollo de variedad desplegado entre los siglos XV, XVI y mediados del XVII se relaciona también con importantes fenómenos de «mezcla» entre estilos locales de diferentes regiones y entre estilos locales e incaicos, que de alguna manera son un correlato de las transformaciones y redefiniciones en las relaciones sociales en el interior de los grupos y entre sociedades vecinas condicionadas por las diferentes situaciones de expansión imperial vividas (Marchegiani et al. 2009).

Debido a elecciones o limitaciones que se nos escapan se difundieron en la región de Yocavil y alrededores cambios en el sistema de diseños santamarianos que llevaron, si no a su desaparición, a una notable disminución y transformaciones en los patrones de empleo del pigmento rojo en las épocas más tardías de su producción. Los ejemplos que hemos descrito en este trabajo, sin embargo, nos muestran la pervivencia y la fuerza del simbolismo de la combinación los colores blanco, negro y rojo que durante siglos se articularon en la codificación de significados de acuerdo con pautas estéticas muy definidas y duraderas.

Agradecimientos: Este trabajo es una reelaboración de la monografía presentada en el seminario doctoral de la Facultad de Filosofía y Letras, Universidad de Buenos Aires «Nuevas 
perspectivas de prehistoria regional andina. Complejización social en los Andes meridionales y centro sur». Agradezco a los profesores Verónica Williams y Calogero Santoro sus observaciones a la primera versión y a Myriam Tarragó, Gerónimo Pratolongo, Alejandra Reynoso y Marina Marchegiani por sus comentarios a una versión posterior.

\section{Referencias bibliográficas}

BALDINI, Lidia

1980 «Dispersión y cronología de las urnas de tres cinturas en el Noroeste argentino». Relaciones de la Sociedad Argentina de Antropología 14 (1): 49-61

BASE DE DATOS IAMUNT

2003 Base de datos de la colección arqueológica del Instituto de Arqueología y Museo [CD-ROM]. Tucumán: Universidad Nacional de Tucumán - Fundación Tiempos Fundación CEPPA.

BREgANTE, Odilia

1926 Ensayo de clasificación de la cerámica del Noroeste argentino. Buenos Aires: Ángel Estrada y Cía. Editores.

BRuch, Carlos

1911 «Exploraciones arqueológicas en las provincias de Tucumán y Catamarca». Revista del Museo de La Plata 19: 1-209.

CAviglia, Sergio Esteban

1985 Las urnas para niños de los valles Yocavil y Calchaquí: su reinterpretación sobre la base de un enfoque gestáltico. Trabajo final para el Seminario de Arqueología I, Facultad de Filosofía y Letras, Universidad de Buenos Aires. MS.

2002 «El arte de las mujeres aónik'enk y gününa küna -kay guaj'enk o kay gütrruj (las capas pintadas)». Relaciones de la Sociedad Argentina de Antropología 27: 41-69.

Cigliano, Eduardo Mario

1958 «Arqueología de la zona de Famabalasto». Revista del Museo de La Plata. Sección Antropología (Nueva Serie) 5: 29-122.

DEBENEDETTI, Salvador

1921 La influencia hispánica en los yacimientos arqueológicos de Caspinchango (Provincia de Catamarca). Publicaciones de la Sección Antropología, 20. Buenos Aires: Universidad de Buenos Aires.

Douglass, Amy y Owen Lindauer

1988 «Hierarchical and Nonhierarchical Approaches to Ceramic Design Analysis: A Response to Jernigan». American Antiquity 53 (3): 620-626.

GonZÁLEZ, Alberto Rex

1955 «Contextos culturales y cronología relativa en el área Central del N. O. argentino (nota preliminar)». Anales de Arqueología y Etnología 9: 7-32.

1992 Las placas metálicas de los Andes del Sur. Contribución al estudio de las religiones precolombinas. Mainz am Rhein: Materialien zur Allgemeinen und Vergleichenden Archáologie Band 46. KAVA.

Greco, Catriel

2012 Integración de datos arqueológicos, radiocarbónicos y geofísicos para la cons- 
trucción de una cronología de Yocavil y alrededores. Tesis Doctoral. Buenos Aires: Facultad de Filosofía y Letras, Universidad de Buenos Aires.

JERNIGAN, E. Wesley

1986 «A Non-Hierarchical Approach to Ceramic Decoration Analysis: A Southwestern Example». American Antiquity 51 (1): 3-20.

Marchegiani, Marina, Valeria Palamarczuk y Alejandra Reynoso

2009 «Las urnas Negro sobre Rojo tardías de Yocavil (Noroeste Argentino). Reflexiones en torno al estilo». Boletín del Museo Chileno de Arte Precolombino 14 (1): 69-98.

Márquez Miranda, Fernando y Eduardo Mario Cigliano

1957 «Ensayo de una clasificación tipológico-cronológica de la cerámica santamariana». Notas de El Museo de La Plata. Sección Antropología 19 (68): 1-28.

NASTRI, Javier

1999 «El estilo cerámico santamariano de los Andes del sur (siglos XI a XVI)». Baessler-Archiv, Neue Folgue 47: 361-396.

PalAmarczuK, Valeria

2011 Un estilo y su época. El caso de la cerámica Famabalasto Negro Grabado del Noroeste Argentino. BAR International Series 2243. Oxford: Archaeopress.

Perrota, Elena y Clara Podestá

1974 Seriación con valor cronológico de una colección de urnas y pucos santamarianos del valle de Yocavil. Ponencia presentada en el III Congreso Nacional de Arqueología Argentina, Salta. MS.

PIÑEIRO, Mónica

1997 La producción cerámica especializada. Desarrollo tecnológico e implicancias socioeconómicas a partir del estudio de la variabilidad individual en los restos materiales. Informe Final de Beca de Iniciación de la Universidad de Buenos Aires. MS.

Podestá, Clara y Elena Perrotta

1973 «Relaciones entre culturas del Noroeste Argentino. San José y Santa María». Antiquitas 17: 6-15.

ReYnoso, Alejandra y Gerónimo Pratolongo

2008 «Jaguares de nuevo. Consideraciones sobre la temática felínica en la iconografía cerámica del período tardío en Yocavil (Noroeste argentino)». Estudios Atacameños 35: 76-96.

SERrano, Antonio

1958 Manual de cerámica indígena. Córdoba: Editorial Assandri.

1967 «Historia cultural del Tucumán prehispánico (una introducción a la arqueología del Noroeste argentino)». Ampurias 19: 1-66.

SHEPARD, Anna O.

1957 Ceramics for the Archaeologist. Publication 609. Washington, D.C.: Carnegie Institution of Washington.

TARRAGó, Myriam Noemí

1984 «El contacto hispano-indígena: la provincia de Chicoana». Runa 14: 143-185. 
Velandia Jagua, Cesar Augusto

2005 Iconografía funeraria en la cultura Santa María, Argentina. Ibagué: Universidad de Tolima.

Wagner, Duncan y Emilio Wagner

1934 La civilización chaco-santiagueña y sus correlaciones con las del Viejo y Nuevo Mundo. Buenos Aires: Compañía Impresora Argentina.

WEBER, Ronald

1978 «A Seriation of the Late Prehistoric Santa María Culture in Northwestern Argentina». Fieldiana Anthropology 68 (2): 49-98.

WEISER, Vladimiro

1921 Libreta de campo 16, III Expedición.

WeISER, Vladimiro y Friedrich WoLTERS

1921-22 Libretas de campo 18 y 21, IV Expedición.

1923-24 Libretas de campo 25 y 26, VI Expedición. 